\title{
The Effect of Using Minor Games in Athletics and Swimming on Some Immunoglobulin, Interferon andPhysical Variables for Children (Age Group 8 - 11 Years Old)
}

\author{
Dina Ali Mohamed Said*, Shaimaa Mohamed Nagib Hassan**
}

The researchers conducted a study that aims to identify the effect of the three minor games programs (Floor Program, Aquatic Program, and Floor /Aquatic Program) on some immunoglobulin, interferon and physical variables for children (age group 8-11 years old.) And the best effect minor games. The researchers used the experimental method by using three experimental groups through pre and post measurements for each group, a purposive sample of (52) orphan children ranged in age from 8-11 years, were divided randomly into three groups; (12) children each, for a period of three months, (3) days per week., the most important results obtained is indicating that: the three minor games programs proved to induce positive effect on some immunoglobulin and interferon for children (8- 11 years old). The aquatic program is better than both, the floor program, and the floor-aquatic program. In enhancing the immunity system efficiency also, it has been proved that the three programs had different effect on the physical variables as the floor exercise has led to developing (arm muscles strength, agility, ankles flexibility, and abdominal muscles strength). On the other hand, aquatic exercise has led to raise (Cardiovascular endurance), while floor-aquatic exercise has improved (Leg muscles strength, Back flexibility, Shoulders flexibility, $30 \mathrm{~m}$. speed running, and Back muscular endurance).

Key words:Immunity:

"It refers to the human physical ability of defeating morbid germs, and overcoming such germs in case of infection, and therefore protecting the body from diseases". (1:60)

Immunoglobulin (I g):

"Glycoprotein exists in the blood and other body liquids; it plays the role of the anti-body, all anti-bodies are considered as (I $g$ ) molecule, but not every (I $g$ ) is considered as anti-body. (2: 38)

Interferon:

"A protein molecule which considered as the basic anti-viruses in immunity system and produced by most of the body cells which, in turn, send signals to one another in case of discovering a virus, these signals are chemical compounds, Interferon's function is to stop the process of any virus proliferation. (3)

Minor games:

A group of various games with a sort of particular characteristic, practiced by the individual in a group of individuals without applying any acknowledged or announced conditions, terms, or rules, such games do not belong to any specific institution or undergo any union supervision, and could be practiced by both; males and females, this type of games support the process of improving the physical change. (Procedural definition).

\section{Introduction}

$\mathbf{T}$ The child is considered the focus of interest in all advanced and developed societies, simply speaking, because today's childistomorrow's man.Therefore, the task of raising and taking care of such a child is considered

*Lecturer At The Aquatic Sports Training Department, Faculty Of Physical Education For Girls, Helwan University.

**Lecturer At The Track And Field Training Department, Faculty Of Physical Education For Girls, Helwan University. a long-term plan that aims to develop and support the process of social security for the whole community which is meant to be a typical human investment to pave the way for a new healthy generation.

Along with the rapid scientific progress taking place in the training science, many methodswere invented and established such as using minor games because of its benefits which reflect physical fitness, provide healthy lifestyle and 
flourish skillfull abilities, in addition to containing the element of excitement and competition, which is considered one of the physiological promoting factors.

So games which are lacking in competition element are characterized with slower progress in contrast with those having competitions. Therefore, those interested in sports must change or modify the technicalities and skills by using games that use alternative tools and equipments, suitable in size and weight to make them more appealing and convenient for children.(4)

Minor games represent a very important and vital part in both educational and training activity because of its high value among the other various games and activities, in addition to being a part of a whole in any trainingeducational program designed and applied for the various age groups which aims to enhance the process of improving kinetic, physical, and functional skills and much more, thus suitable training courses could be established and programmed depending on minor games in order to achieve the best results in creating and attaining an advanced physical performance level.(5)

Practicing moderate sport exercises such as walking, swimming and cycling leads to increase the muscular strength, improve the secretion of hormones, increase and regulate metabolism, improve blood circulation, and lead to the occurrence of some changes in the blood defense capability. Where all vital systems are adapted to meet the need of effort and adjust its functions that leads to the increase in the number of white blood cells(leukocytes), leading to the increase of the body immune system efficiency. (4)

The International Athletics Union declared and assured the importance of implying a variety of new, modern and creative competitions in the sport programs designed especially for children (age group 8-11 years old) in order to support the process of developing the elements of basic physical fitness and initial kinetic skills such as: (running, jumping, leaping, pushing, hurling, hurdling, throwing), in addition to raising the spirit of adventure as well as developing the social interaction. $(6: 27)(7: 53,58)$

Moderate swimming (30-60 min, twice per week "at least" ) found to be an aid in improving blood circulation which in turn facilitate the process of distributing the nutrition elements and oxygen to muscles, cells, and the various body systems, benefits of swimming are obvious in increasing the cell's capability to defeat respiratory toxic byproducts and ( $\mathrm{CO} 2$ ) ,swimming is also involved with promoting the functions of the lymphatic system which upgrade the efficiency of distributing white blood cells (leukocytes) all over the various body systems and ,eventually, has a direct influence in improving the immunity system. (5)

Both "Saad Kamal Taha and Ibrahim Yehia Khalil" (2004) refers that the body defends himself in many processes and mechanisms, which include all body parts, of these mechanisms are the specialized and nonspecialized defensive methods carried out by the blood. Interferon (IFN) is one of the blood defensive methods that are cellular stimulators produced naturally by the body and one of the important elements in supressing the viral infection, inhibiting viruses' proliferation and the division of cancer cells. The blood specialized defensive methods is carried out by the Beta-lymphocytes cells responsible for forming the antibodies (immunoglobulin or immunoproteins) such as IGG, IGM and IGA. (2: 37) 
The results of some studies such as "Thomas N. E. et al" (2010) (8), "Reid M. R. et al" (2001) (9), and Mckune A. J. et al. (2005) (10), referred that practicing anaerobic violent exercises for a long period significantly leads to a lack of immune bodies, while walking increases in antibodies, whereas running increases the gulping ability of immunocyte cells. (11)

Many researches referred to the different effect of practicing sport on immunoglobulin, as each of "Francis et al.," (2005) (12), "Petibois et al.," (2003) (13), "Nieman et al.," (2003) (14), and "Nehlsen et al.," (2000) (15) referred to the increase of immunoglobulin (IGA, IGM, IGG) due to the irregularity in the sports program. While "Mashiko T, et al.," (2004) (16) referred to the decrease in this immunoglobulin.

This means that the low-intensity exercises improves the physiological processes, while the medium intensity exercises develops them, and the high intensity exercises are hindering improvement of the physiological processes. The aerobic exercises usually are low in intensity, as it does not cause fatigue, while fatigue is associated with practicing anaerobic exercises; therefore, it increases the ability of the immune system to disease resistance. (17)

And due to the importance of the scientific research role in enriching the community life, both researchers felt the need for cooperation with NGOs for the development of the local communities to provide them with services for orphans of 8-11 years old, as some of those children never practice sports or even athletics and swimming in particular. The importance of this study lies in the interpretation of the changes occurring to the body's immune system because of performing moderate load minor games program in an attempt to reach objective and simple means to raise the efficiency of the immune system in the body. The immune system role for children cannot overlooked, also the role of sport cannot be neglected in raising the body's immunity, and it is a mutual role that may contribute improving both health and physical aspect for these children.

Hence, the idea of the research crystallized as a scientific attempt to identify the effect of minor games programs (floor, aquatic and floor/aquatic) on some immunoglobulin, Interferon and physical variables for children of 8-11 years old.

\section{Aims of the research:}

The research aims to identify the effect of three different games program on the research variables for the children of age $8-11$ years are:

1. The impact of floor games program immunoglobulin and interferon and some physical variables.

2. The impact of water games program immunoglobulin and interferon and some physical variables.

3. The impact of floor -water games program immunoglobulin and interferon and some physical variables.

4. Compared the three programs to recognize the best of these programs impact on some immunoglobulin and interferon and some physical variables.

\section{Materials and methods \\ Subjects}

The researchers used the experimental method by using three experimental groups through pre and post measurements for each group, as it suits the nature of the research.

Society and the sample of the research:

A purposive sample of 52 orphan children from the Tenderness River Association ranged in age from 8-11 years, were divided randomly to (16) child to the pilot study, (36) children were also divided to three groups (12) children each. The first group (Floor Program Group), the second 
group (Aquatic Program Group), and the third group (Floor /Aquatic Program Group).

\section{Tools of collecting data:}

\section{A. Tools and equipments:}

The following tools were used for collecting the required data of the research:

- A Restameter device for measuring height.

- A medical scale for measuring weight $(\mathrm{kg})$.

- A gradual tape for the anthropometric measurements (lengths, widths, and perimeters).

- Test tubes, cotton, syringes, alcohol, heparin to prevent blood clots, gloves, and ELISA Assay for measuring immunoglobulin (IGG, IGM and IGA) and interferon.

\section{B. Questionnaires and interviews:}

The researchers have used four questionnaires for collecting the expert's opinion as follows:

- A questionnaire to determine the most important physical variables.

- A questionnaire to determine the suitability of the physical variables.

- A questionnaire of athletics to determine the suitability of the minor games to the age stage on topics.

- A questionnaire of swimming to determine the suitability of the minor games to the age stage on topics.

\section{Physical variables tests:}

The researchers selected the most suitable test that measure the physical variables and agreed upon by the experts, as follows:

- Broad jump from stability test for measuring legs muscles power.

- Pushing a medicine ball (weighted 3kg.) test for measuring arm and shoulder muscular power.

- Zigzag running between hurdles test (time) for measuring agility.
- Bridge test for measuring the backbone flexibility.

- Raising shoulder test for measuring shoulders flexibility.

- Ankle angel test for measuring ankle flexibility.

- 30 meters speed running test from a moving start for measuring speed.

- Raising legs high test for measuring abdominal muscular endurance.

- Raising chest high test for measuring back muscular endurance.

- Sitting from lying down in 20 seconds test for measuring abdominal muscular power.

- Shuttle run test (5 X55m.).

\section{The Suggested programs}

The researchers had designed three programs (floor program, Aquatic program, Floor-Aquatic program), these programs aimed to rise and upgrade the immunity level represented in some immunoglobulin and interferon for the sample (orphan children), in addition to improve some of their physical changes.

The researchers took care of: implying a time period for warming up and preparing the children's bodies for training, the convenience between the programs and the age group category along with their skill level capabilities, as well as the individual differences, and the variety in program, and inside the groups and during time periods, games should be characterized by excitement and motivation.

\section{Applying the main research experiment:}

The research experiment was applied in the Faculty of Physical Education for Girls' pool for thethree research samples (floor program group, aquatic program group, and the floor/aquatic program group), for a period of three months, represented in (10) weeks, as (30) units in (6)days per week. Divided to (3) days for both the floor program, and aquatic program groups 
and (3) days for the floor/aquatic program group. Exercises start at 09.00 to 10.00 a.m. on Saturday, Monday and Wednesday for both the floor program, and aquatic program groups, and on Sunday, Tuesday and Thursday for the floor/aquatic program group. The researchers alternated exercises times between groups each two weeks by a round robin manner.

\section{Results}

Table (1)

Significant differences and the improvement rates between pre and post measurements of the research three groups in some immunoglobulin and interferon

$N=12$

\begin{tabular}{|c|c|c|c|c|c|c|c|c|}
\hline \multirow{2}{*}{ Variables } & \multirow{2}{*}{$\begin{array}{l}\text { Measuring } \\
\text { unit }\end{array}$} & \multirow{2}{*}{ Groups } & \multicolumn{2}{|c|}{$\begin{array}{c}\text { Pre } \\
\text { measurement }\end{array}$} & \multicolumn{2}{|c|}{$\begin{array}{c}\text { Post } \\
\text { measurement }\end{array}$} & \multirow{2}{*}{$\begin{array}{l}\text { "T" } \\
\text { Value }\end{array}$} & \multirow{2}{*}{$\begin{array}{l}\text { Improvement } \\
\text { rate } \%\end{array}$} \\
\hline & & & $\mathbf{A M}$ & SD & $\mathbf{A M}$ & SD & & \\
\hline \multirow{3}{*}{$\mathrm{IgG}$} & \multirow{3}{*}{$\mathrm{Mg}$} & 1 & 1257.08 & 90.77 & 1359.58 & 113.87 & $3.20 *$ & 8.15 \\
\hline & & 2 & 1242.92 & 109.72 & 1505 & 63.75 & $8.24 *$ & 21.09 \\
\hline & & 3 & 1208.92 & 127.52 & 1332.5 & 131.97 & $3.32 *$ & 10.22 \\
\hline \multirow{3}{*}{$\operatorname{Ig} \mathrm{A}$} & \multirow{3}{*}{$\mathrm{Mg}$} & 1 & 180.83 & 27.37 & 203.33 & 36.39 & $2.76 *$ & 12.44 \\
\hline & & 2 & 207.5 & 44.59 & 309.58 & 24.44 & $9.18 *$ & 49.19 \\
\hline & & 3 & 182.17 & 36.52 & 277.67 & 41.08 & $5.28 *$ & 52.42 \\
\hline \multirow{3}{*}{$\operatorname{IgM}$} & \multirow{3}{*}{$\mathrm{Mg}$} & 1 & 210 & 44.67 & 230.83 & 38.48 & $3.51 *$ & 9.92 \\
\hline & & 2 & 208.58 & 43.42 & 285.83 & 26.44 & $5.90 *$ & 37.04 \\
\hline & & 3 & 201 & 39.01 & 256.67 & 29.92 & $4.94 *$ & 27.69 \\
\hline \multirow{3}{*}{$\gamma \mathrm{IN}$} & \multirow{3}{*}{$\mathrm{Iu} / \mathrm{ml}$} & 1 & 0.32 & 0.07 & 0.39 & 0.04 & $3.87 *$ & 21.88 \\
\hline & & 2 & 0.32 & 0.05 & 0.52 & 0.05 & $15.36^{*}$ & 62.5 \\
\hline & & 3 & 0.29 & 0.05 & 0.45 & 0.06 & $9.04 *$ & 55.17 \\
\hline
\end{tabular}

*The indexed "T" value at the significant level of $0.05=2.20$

Table (2)

Significant differences between the research three groups in the post-measurement in some immunoglobulin and Interferon $N=36$

\begin{tabular}{|c|c|c|c|c|c|}
\hline Variables & Variation source & Sum of squares & Freedom degrees & Average of squares & $\begin{array}{c}\text { "F" } \\
\text { Value }\end{array}$ \\
\hline \multirow{2}{*}{$\operatorname{IgG}$} & Between & 235209.7 & 2 & 117604.9 & \multirow{2}{*}{$8.76^{*}$} \\
\hline & Within & 443163.9 & 33 & 13429.21 & \\
\hline \multirow{2}{*}{$\operatorname{IgA}$} & Between & 89276.06 & 2 & 44638.03 & \multirow{2}{*}{$44.09^{*}$} \\
\hline & Within & 33406.25 & 33 & 1012.31 & \\
\hline \multirow{2}{*}{$\operatorname{IgM}$} & Between & 27505.56 & 2 & 13752.78 & \multirow{2}{*}{$15.38^{*}$} \\
\hline & Within & 29507 & 33 & 894.15 & \\
\hline \multirow{2}{*}{$\gamma$ IFN } & Between & 0.1 & 2 & 0.05 & \multirow{2}{*}{$18.23^{*}$} \\
\hline & Within & 0.09 & 33 & 0.003 & \\
\hline
\end{tabular}

*The indexed " $F$ " value at the significant level of $0.05=3.28$ 
Table (3)

Significant differences between the research three groups averages in the post-measurement in some immunoglobulin and Interferon

\begin{tabular}{|c|c|c|c|c|c|c|}
\hline Variables & Averages & Groups & 1 & 2 & 3 & Value of Cheviet test \\
\hline \multirow{3}{*}{$\operatorname{IgG}$} & 1359.58 & 1 & & $170.42 *$ & 2.08 & \multirow{3}{*}{121.17} \\
\hline & 1505 & 2 & & & $172.5^{*}$ & \\
\hline & 1332.5 & 3 & & & & \\
\hline \multirow{3}{*}{$\operatorname{Ig} \mathrm{A}$} & 203.33 & 1 & & $117.92^{*}$ & $86.00 *$ & \multirow{3}{*}{33.27} \\
\hline & 309.58 & 2 & & & $33.91 *$ & \\
\hline & 277.67 & 3 & & & & \\
\hline \multirow{3}{*}{$\operatorname{IgM}$} & 230.83 & 1 & & $76.50 *$ & $38.33 *$ & \multirow{3}{*}{31.27} \\
\hline & 285.83 & 2 & & & 29.17 & \\
\hline & 256.67 & 3 & & & & \\
\hline \multirow{3}{*}{$\gamma$ IFN } & 0.39 & 1 & & $0.13 *$ & $0.06 *$ & \multirow{3}{*}{0.06} \\
\hline & 0.52 & 2 & & & $0.07 *$ & \\
\hline & 0.45 & 3 & & & & \\
\hline
\end{tabular}

Table (3) illustrates the places of differences between the research three groups' averages in immunoglobulin and interferon.

Table (4)

Significant differences and the improvement rates between pre and post measurements of the three research groups in the physical variables

\begin{tabular}{|c|c|c|c|c|c|c|c|c|}
\hline \multicolumn{9}{|c|}{$N=12$} \\
\hline \multirow{2}{*}{ Variables } & \multirow{2}{*}{$\begin{array}{c}\text { Measuring } \\
\text { unit }\end{array}$} & \multirow{2}{*}{ Groups } & \multicolumn{2}{|c|}{$\begin{array}{c}\text { Pre } \\
\text { measurement }\end{array}$} & \multicolumn{2}{|c|}{$\begin{array}{c}\text { Post } \\
\text { measurement }\end{array}$} & \multirow{2}{*}{$\begin{array}{c}\text { "T" } \\
\text { Value }\end{array}$} & \multirow{2}{*}{$\begin{array}{l}\text { Improvement } \\
\text { rate } \%\end{array}$} \\
\hline & & & $\mathrm{AM}$ & $\mathrm{SD}$ & $\mathrm{AM}$ & SD & & \\
\hline \multirow{3}{*}{$\begin{array}{l}\text { Leg muscles } \\
\text { power }\end{array}$} & \multirow{3}{*}{$\mathrm{Cm}$. } & 1 & 124.83 & 20.6 & 139.25 & 16.67 & $7.31 *$ & $11.55 \%$ \\
\hline & & 2 & 122 & 19.1 & 129.42 & 18.69 & $6.14 *$ & $6.08 \%$ \\
\hline & & 3 & 119.67 & 24.01 & 149 & 19.22 & $11.75^{*}$ & $24.51 \%$ \\
\hline \multirow{3}{*}{$\begin{array}{c}\text { Arm muscles } \\
\text { power }\end{array}$} & \multirow{3}{*}{ meter } & 1 & 8.03 & 1.86 & 10.75 & 1.87 & $10.67 *$ & $33.87 \%$ \\
\hline & & 2 & 7.96 & 1.73 & 8.96 & 1.87 & $6.60 *$ & $12.56 \%$ \\
\hline & & 3 & 7.83 & 1.64 & 9.98 & 1.12 & $6.32 *$ & $27.46 \%$ \\
\hline \multirow{3}{*}{ Agility } & \multirow{3}{*}{ seconds } & 1 & 8.02 & 1.42 & 5.81 & 0.77 & $5.54 *$ & $27.56 \%$ \\
\hline & & 2 & 8.1 & 1.04 & 7.07 & 0.93 & $7.40^{*}$ & $12.72 \%$ \\
\hline & & 3 & 7.88 & 1.1 & 6.27 & 0.22 & $5.16^{*}$ & $20.43 \%$ \\
\hline \multirow{3}{*}{$\begin{array}{c}\text { Back } \\
\text { flexibility }\end{array}$} & \multirow{3}{*}{$\mathrm{Cm}}$. & 1 & 44.5 & 5.42 & 41.58 & 5.62 & $8.15^{*}$ & $6.56 \%$ \\
\hline & & 2 & 43.5 & 6.04 & 41.58 & 5.95 & $4.60 *$ & $4.41 \%$ \\
\hline & & 3 & 43.42 & 5.25 & 36.08 & 2.43 & $6.30 *$ & $16.90 \%$ \\
\hline \multirow{3}{*}{$\begin{array}{l}\text { Shoulders } \\
\text { flexibility }\end{array}$} & \multirow{3}{*}{$\mathrm{Cm}$. } & 1 & 68.5 & 5.18 & 62.42 & 5.19 & $11.83^{*}$ & $8.88 \%$ \\
\hline & & 2 & 68.5 & 5 & 66.25 & 5.17 & $10.34 *$ & $3.28 \%$ \\
\hline & & 3 & 68.33 & 5.02 & 61.17 & 4.34 & $11.24 *$ & $10.48 \%$ \\
\hline \multirow{2}{*}{$\begin{array}{l}\text { Ankles } \\
\text { flexibility }\end{array}$} & \multirow{2}{*}{$\mathrm{Cm}}$. & 1 & 10.83 & 2.48 & 7.5 & 1.62 & $10.76^{*}$ & $30.75 \%$ \\
\hline & & 2 & 10.92 & 2.5 & 9.83 & 2.17 & $4.17 *$ & $9.98 \%$ \\
\hline
\end{tabular}


Dina Ali Mohamed Said, Shaimaa Mohamed Nagib Hassan

\begin{tabular}{|c|c|c|c|c|c|c|c|c|}
\hline & & 3 & 10.5 & 2.43 & 7.25 & 1.71 & $8.74 *$ & $30.95 \%$ \\
\hline \multirow{3}{*}{$\begin{array}{l}30 \mathrm{~m} . \text { speed } \\
\text { running }\end{array}$} & \multirow{3}{*}{ seconds } & 1 & 6.62 & 0.84 & 5.33 & 0.59 & $12.43^{*}$ & $19.49 \%$ \\
\hline & & 2 & 6.48 & 0.71 & 5.68 & 0.64 & $9.49 *$ & $12.35 \%$ \\
\hline & & 3 & 6.8 & 1.25 & 4.85 & 0.56 & $5.42 *$ & $28.68 \%$ \\
\hline \multirow{3}{*}{$\begin{array}{l}\text { Abdominal } \\
\text { muscular } \\
\text { endurance }\end{array}$} & \multirow{3}{*}{ seconds } & 1 & 15.86 & 5.72 & 22.12 & 5.23 & $6.60^{*}$ & $39.47 \%$ \\
\hline & & 2 & 16.86 & 5.02 & 20.45 & 3.73 & $5.22 *$ & $21.29 \%$ \\
\hline & & 3 & 14.85 & 4.95 & 22.69 & 3.64 & $5.67 *$ & $52.79 \%$ \\
\hline \multirow{3}{*}{$\begin{array}{l}\text { Back muscular } \\
\text { endurance }\end{array}$} & \multirow{3}{*}{ seconds } & 1 & 43.94 & 6.53 & 52.27 & 4.15 & $8.83^{*}$ & $18.96 \%$ \\
\hline & & 2 & 44.54 & 6.78 & 48.09 & 7.27 & $6.69 *$ & $7.97 \%$ \\
\hline & & 3 & 43.66 & 5.65 & 54.71 & 4.08 & $12.14^{*}$ & $25.31 \%$ \\
\hline \multirow{3}{*}{$\begin{array}{l}\text { Cardiovascular } \\
\text { endurance }\end{array}$} & \multirow{3}{*}{ seconds } & 1 & 18.85 & 1.21 & 17.49 & 0.85 & $5.81^{*}$ & $7.21 \%$ \\
\hline & & 2 & 18.49 & 1.15 & 16.44 & 0.42 & $6.00 *$ & $11.09 \%$ \\
\hline & & 3 & 18.53 & 1.32 & 16.29 & 0.72 & $6.61 *$ & $12.09 \%$ \\
\hline \multirow{3}{*}{$\begin{array}{c}\text { Abdominal } \\
\text { muscles power }\end{array}$} & \multirow{3}{*}{ number } & 1 & 4.44 & 10.92 & 19.92 & 3.6 & $17.23^{*}$ & $82.42 \%$ \\
\hline & & 2 & 4.78 & 10.83 & 14.33 & 4.36 & $15.20 *$ & $32.32 \%$ \\
\hline & & 3 & 3.33 & 9.25 & 18.08 & 3.09 & $21.80^{*}$ & $95.46 \%$ \\
\hline
\end{tabular}

*The indexed "T" value at the significant level of $0.05=2.20$

Table (5)

Significant differences between the research three groups in the post-measurement in the physical variables $N=36$

\begin{tabular}{|c|c|c|c|c|c|}
\hline Variables & $\begin{array}{c}\text { Variation } \\
\text { source }\end{array}$ & $\begin{array}{l}\text { Sum of } \\
\text { squares }\end{array}$ & $\begin{array}{c}\text { Freedom } \\
\text { degrees }\end{array}$ & $\begin{array}{c}\text { Average of } \\
\text { squares }\end{array}$ & "F" Value \\
\hline \multirow{2}{*}{ Leg muscles power. } & Between & 2301.06 & 2 & 1150.53 & \multirow{2}{*}{$3.46^{*}$} \\
\hline & Within & 10963.17 & 33 & 332.22 & \\
\hline \multirow{2}{*}{ Arm muscles power } & Between & 19.25 & 2 & 9.63 & \multirow{2}{*}{$3.51^{*}$} \\
\hline & Within & 90.54 & 33 & 2.74 & \\
\hline \multirow{2}{*}{ Agility } & Between & 9.75 & 2 & 4.88 & \multirow{2}{*}{$9.77 *$} \\
\hline & Within & 16.46 & 33 & 0.49 & \\
\hline \multirow{2}{*}{ Back flexibility } & Between & 242 & 2 & 121 & \multirow{2}{*}{$4.99 *$} \\
\hline & Within & 800.75 & 33 & 24.27 & \\
\hline \multirow{2}{*}{ Shoulders flexibility } & Between & 168.39 & 2 & 84.19 & \multirow{2}{*}{$3.48^{*}$} \\
\hline & Within & 798.83 & 33 & 24.21 & \\
\hline \multirow{2}{*}{ Ankles flexibility } & Between & 48.72 & 2 & 24.36 & \multirow{2}{*}{$7.12 *$} \\
\hline & Within & 112.92 & 33 & 3.42 & \\
\hline \multirow{2}{*}{$30 \mathrm{~m}$. speed running } & Between & 4.12 & 2 & 2.06 & \multirow{2}{*}{$5.81 *$} \\
\hline & Within & 11.7 & 33 & 0.36 & \\
\hline \multirow{2}{*}{$\begin{array}{l}\text { Abdominal muscular } \\
\text { endurance }\end{array}$} & Between & 32.74 & 2 & 16.37 & \multirow{2}{*}{0.9} \\
\hline & Within & 600.11 & 33 & 18.19 & \\
\hline \multirow{2}{*}{$\begin{array}{l}\text { Back muscular } \\
\text { endurance }\end{array}$} & Between & 269.05 & 2 & 134.53 & \multirow{2}{*}{$4.66^{*}$} \\
\hline & Within & 953.18 & 33 & 28.88 & \\
\hline \multirow{2}{*}{$\begin{array}{l}\text { Cardiovascular } \\
\text { endurance }\end{array}$} & Between & 10.16 & 2 & 5.08 & \multirow{2}{*}{$10.57 *$} \\
\hline & Within & 15.86 & 33 & 0.48 & \\
\hline \multirow{2}{*}{$\begin{array}{l}\text { Abdominal muscles } \\
\text { power }\end{array}$} & Between & 194.39 & 2 & 97.19 & \multirow{2}{*}{$7.03^{*}$} \\
\hline & Within & 456.5 & 33 & 13.83 & \\
\hline
\end{tabular}

*The indexed " $F$ " value at the significant level of $0.05=3.28$ 
Table (6)

Significant differences between the research three groups averages in the physical variables.

\begin{tabular}{|c|c|c|c|c|c|c|}
\hline Variables & Averages & Groups & 1 & 2 & 3 & $\begin{array}{c}\text { Value of } \\
\text { Cheviet test }\end{array}$ \\
\hline \multirow{3}{*}{$\begin{array}{l}\text { Leg muscles } \\
\text { power. }\end{array}$} & 139.25 & 1 & & 9.8 & 9.75 & \multirow{3}{*}{19.06} \\
\hline & 129.42 & 2 & & & $19.58 *$ & \\
\hline & 149 & 3 & & & & \\
\hline \multirow{3}{*}{$\begin{array}{l}\text { Arm muscles } \\
\text { power }\end{array}$} & 10.75 & 1 & & $1.79 *$ & 0.77 & \multirow{3}{*}{1.73} \\
\hline & 8.96 & 2 & & & 1.01 & \\
\hline & 9.98 & 3 & & & & \\
\hline \multirow{3}{*}{ Agility } & 5.81 & 1 & & $1.26^{*}$ & 0.46 & \multirow{3}{*}{0.73} \\
\hline & 7.07 & 2 & & & $0.79 *$ & \\
\hline & 6.27 & 3 & & & & \\
\hline \multirow{3}{*}{ Back flexibility } & 41.58 & 1 & & 0.01 & $5.5^{*}$ & \multirow{3}{*}{5.15} \\
\hline & 41.58 & 2 & & & $5.5^{*}$ & \\
\hline & 36.08 & 3 & & & & \\
\hline \multirow{3}{*}{$\begin{array}{l}\text { Shoulders } \\
\text { flexibility }\end{array}$} & 62.42 & 1 & & $3.83 *$ & 1.25 & \multirow{3}{*}{3.14} \\
\hline & 66.25 & 2 & & & $5.08 *$ & \\
\hline & 61.17 & 3 & & & & \\
\hline \multirow{3}{*}{ Ankles flexibility } & 7.5 & 1 & & $2.33 *$ & 0.25 & \multirow{3}{*}{1.93} \\
\hline & 9.83 & 2 & & & $2.58 *$ & \\
\hline & 7.25 & 3 & & & & \\
\hline \multirow{3}{*}{$\begin{array}{l}30 \text { m. speed } \\
\text { running }\end{array}$} & 5.33 & 1 & & 0.35 & $0.48 *$ & \multirow{3}{*}{0.44} \\
\hline & 5.68 & 2 & & & $0.83 *$ & \\
\hline & 4.85 & 3 & & & & \\
\hline \multirow{3}{*}{$\begin{array}{l}\text { Back muscular } \\
\text { endurance }\end{array}$} & 52.27 & 1 & & 4.18 & 2.44 & \multirow{3}{*}{5.62} \\
\hline & 48.09 & 2 & & & $6.62 *$ & \\
\hline & 54.71 & 3 & & & & \\
\hline \multirow{3}{*}{$\begin{array}{c}\text { Cardiovascular } \\
\text { endurance }\end{array}$} & 17.49 & 1 & & $1.05^{*}$ & $1.19 *$ & \multirow{3}{*}{0.72} \\
\hline & 16.44 & 2 & & & 0.15 & \\
\hline & 16.29 & 3 & & & & \\
\hline \multirow{3}{*}{$\begin{array}{c}\text { Abdominal } \\
\text { muscles power }\end{array}$} & 19.92 & 1 & & $5.58 *$ & 1.83 & \multirow{3}{*}{3.89} \\
\hline & 14.33 & 2 & & & 3.75 & \\
\hline & 18.08 & 3 & & & & \\
\hline
\end{tabular}

Table (6) illustrates the places of differences between the research three groups averages in the physical variables on topics.

\section{Discussion}

Table (1) illustrates that there are statistical significant differences between pre and post measurements for the three research groups (floor program, aquatic program and floor/aquatic program) in favor of the post measurement in all immunoglobulin and IFNmeasured. That improvement is due to the three research groups have been subject to moderate 
standardized training programs based on scientific fundamentals. This is consistent with "Abu El-ElaAbd El-Fattah" (1996) that the training and practicing sports according to correct scientific fundamentals lead to strengthen and improving the efficiency of the immune system. (18: 86)

This is consistent with the results of each of "HendAbd El-Razik and Samah Hassan" (2008) (19), "Tobias I. et al.," (2002) (20), and "Pederson B. K., Toft A. D." (2000) (21), that low and moderate intensity training leads to increase the efficiency of the immune system while training with high intensity leads to weaken the immune system and increase the components of inflammation (cytokine).

These results differentiate with the results of the "Alexander Moreira A. et al.," (2010) (22) where samples taken directly after the effort, that may be accompanied by tension resulting in an increase in the adrenaline and Cortisol secretion, which works to reduce the interferon lymphocytes secretion. The researchers return that variation to the time of taking the measurements, where in the recent research measurements taken at rest at the beginning and end of the program, meaning it study the immune system adaptive to the training program, while the aforementioned researchers studied the immune response meaning the acute effect of practicing the physical activity.

By reviewing these results, the researchers returns the reason to the immune system adaptation to the minor games programs to that (IgM) is considered one of the fastest response antibody to any microbe succeed to cross the primary immunocyte, such as (IgA). Moreover, influenced by sports effort "remnants of fatigue," leading to increased levels as a fast response to some products such as lactate, electrolytes and many microbes that increasingly repulse with rapid breathing (tachypnea). But low (IgM) ratio indicates the increase of the primary immune such as physical inhibitions, which prevent the entry of microbes, such as skin and epithelial cells lining the nose, mouth and airways, where (IgA) concentration increases. In addition to the decrease of fatigue remnants' as a result of body and the immune system adaptation to the effort and the training program.
Table (2) illustrates that there are differences between the three research groups in some immunoglobulin and interferon, and Table (3) illustrates the places of these differences showing that the aquatic program group registered the highest improvement percentage in the variables on topics than the other groups, followed by floor/aquatic group, while the least registered improvement was the floor group. That refers to the fact that practicing minor games in the aquatic program was more effective and influential on the immunoglobulin and interferon on topics.

In the researchers opinion, the significant difference between the research groups due to the environment of practicing the exercises, whether this environment is floor, aquatic or floor/aquatic, indicating the importance of determining the training venue that achieves the best immune response because it affected by many factors, including climatic conditions. Moreover, this difference in the increase of (IGA) change's percentage than the other variables may be due to the relation of (IGA) to respiratory system and respiratory paths. The player confronts more challenges when practicing sport in an aquatic medium than floor medium, such as movement water resistance, water temperature, water pressure on the chest, and challenges of performance. That was confirmed by "Francis et al.," (2005) (12) that the IGA, and IGG concentration of swimmers are the double than for non-participating in sport activity. These results are consistent to the results of "Petibois et al.," (2003) (13), and "Nieman et al.," (2003) (14), and "Nehlsen et al.," (2000) (15), which refer that practicing swimming led to increasing the immunoglobulin (IGM, and IGA) as a result of water training.

The recent research results were different from the results of "Thomas et al" (2010) (8), "Reid M. R. et al" (2001) (9), and "Mckune A. J. et al" (2005) (10) in the lack of IgA immunoglobulin due to the regularity in a training program for developing high intensity endurance.

The researchers returns that to the nature of the program, where the researchers used average intensity minor games program, but these studies used a program of high intensity, and this was confirmed by "Tobias et al" (2002) (20) that moderate and low intensity training leads to 
an increase in the efficiency of the immune system.

The researchers suggest that the increased interferon (IFN) is a natural result of the increased formation of immunoglobulin on topics. That is consistent with the results of "Starkia R. L. et al" (2001) (23), where practicing physical activity leads to increasing lymphocyte cells and the natural killer cells, which in turn lead to increased formation of immunoglobulin produced by Betaimmunoglobulin cells. Subsequently an increase in the player immune ability against infections occurs that he might exposed to through activating the specialized defense mechanisms represented in increasing immunoglobulin (IGA, IGM, and IGG) on topics and increasing the non-specialized defense mechanisms represented in increasing interferon (IFN).

These results indicate that the suggested program in the aquatic medium is better than the floor program and the floor/aquatic program in increasing the efficiency of the immune system.

As indicated in the results of table (4) that there are statistically significant differences between pre and post measurements for the three research groups (floor program, aquatic program and floor/aquatic program) in favor of the post measurement in the physical variables. These results may be due to the use of minor games characterized by the large number and diversity of interesting methods that help to increase the participant enjoyment of training. Moreover, they helped to increase their resistance to fatigue and make the effort to push them towards better performance, and works as an assistant factor to make children eager to perform.

In the opinion of the researchers, these results may return to the regularity in training, which led to a high level of physical efficiency, and to the role played by minor games to induce the participant's motives to attend the training. These results are also consistent with "Peter" (2009) (7), "Mohammed Abd El-Rahman" (2006) (25), and "Marwa Youssef" (2000) (26), that the minor games programs in the form of new funny competitive competitions new provide the children with opportunities to train in the best methods for developing the physical variables.
The researchers refers that these games develop the competition spirit by comparing the progress of each child with his colleagues and allowing them equal opportunity to win, which leads to exert maximum effort that helps to improve the physical variables on topics.

Table (5) illustrates that there are significant differences between the three research groups (floor program, aquatic program and floor/aquatic program) in all the physical variables in favor of the post measurement except for the of abdomen muscular endurance test. Table (6) illustrates the significant differences between the groups in the physical tests on topics. Moreover, illustrates that there are significant differences between the floor and aquatic groups in each of pushing a medicine ball, zigzag running, shoulders flexibility and the abdominal muscles strength, and shows that there is a significant difference between the floor and floor/aquatic groups in the back flexibility.

The aforementioned, refers that there is a different effect of the practiced activity on some physical fitness elements. Thus, floor training works on developing (muscular arms power, agility, ankles flexibility, and the abdominal muscles power), while aquatic training works on developing (the cardiovascular endurance), and the floor/aquatic training works on developing (the legs muscular power, back flexibility, shoulders flexibility, $30 \mathrm{~m}$ speed running, and back muscular endurance).

\section{Conclusion}

Regarding the study results, and according to both the sample and statistical treatment the researchers conducted the following:

1) Training and sport exercise based on correct scientific principles resulted in significant improvement and enhancing the efficiency of the immunity system.

2) Applying the three minor games programs proved to have a positive impact upon both; Interferon and Immunoglobulin in children (age group 8-10 years old).

3) Aquatic program proved to be better than both; floor program and floor- aquatic program 
in increasing the efficiency of the immunity system.

4) The three minor games programs had a positive impact on the physiological changes represented in (legs' muscular strength, arms' muscular strength, agility, back flexibility, shoulders' flexibility, ankles' (heels') flexibility, $30 \mathrm{~m}$. speed running ,back muscular endurance, cardiovascular endurance, abdominal muscular strength).

5) Appling the training in a systemic manner (floor, aquatic, floor-aquatic) had various different impacts on developing the physiological changes; the floor training led to (arms' muscular strength, agility, ankles'(heels') flexibility, abdominal muscular strength), while aquatic training led to developing cardiovascular endurance, whereas floor-aquatic program led to developing (legs' muscular strength, back flexibility, shoulders' flexibility, $30 \mathrm{~m}$. speed running back muscular endurance).

6) Minor games proved to be effective method to improve physical fitness in a delightful and humorous atmosphere because of its easiness, simplicity, and excitement.

\section{Recommendations}

The researchers recommended the following;

1) Increasing the share of minor games in sport programs regardless being inside or outside aqua-medium, due to its importance in motivating the children to do more effort during competitions which enhance the process of developing some Interferon and Immunoglobulin, and some physical changes as well.

2) Give the children (age group 8-10 years old) the chance to practice aquatic exercise because of its positive impact in improving some Immunoglobulin and Interferon.

3) Giving more attention to floor-aquatic program training if the aim is to develop the physical changes.
4) The importance of identifying the training place which enhance achieving the best results, it is favorable to apply the aquatic medium training program if the goal is to improve Immunoglobulin and Interferon in children (age group 8-10 years old), but if the goal is to develop and improve physical changes, it is favorable to apply the aquatic medium training program as well as floor training program.

\section{References}

1. Gleeson M., Pyne D. B., Mcdonald W. A., Bowe S. J., Clary R. L., Fricker P. A. (2004): "In- Vinocell mediated immunity in elite swimmers in response to training", national library of medicine.

2. Saad Kamal Taha, and Ibrahim Yehia Khalil (2004): Fundamentals of Physiology, Part II, the Egyptian National Library, Cairo, Egypt.

3. http://www.mhabos.com/Inform/htm.

4. http://www.immunesystemremedies.com/be nefit-of-swimming-exercise.html

5. http://www.livestrong.com/article/545789cardiorespiratory-benefits-of-swimming/

6. Tobias Ibflet, Emil. W, Helle, B, Marie. S, Bete . K (2002): Exercise. Induced change in type 1 cytokine. Producing CD8 tt cells is related to a decrease in memory t cells" . J Applphysiol, Issue. 2.

7. Peter JL Thompson (2009):"Training introduction" International Association of Athletics fedrations

8. Thomas NE, Leyshon A, Hughes MG, Jasper MA, Davies B, Graham MR, Bulloch JM, Baker JS J (2010): "Concentrations of salivary testosterone, cortisol, and immunoglobulin A after supramaximal exercise in female adolescents" Centre for Children and Young People's Health and Well-Being, School of Human and Health Sciences, Swansea University, UK.

9. Reid M.R., Drummond P.D., Mackinnon I.T. (2001): "The effect of Moderate aerobic exercise and relaxation on secretory immunoglobulin A“. International Journal of Sports Medicine, Feb. 
10. Mckune AJ, SmithLL, Semple St, wadee AA (2005): "Influence of Ultra-endurance exercise on immunogolobulinisotypes and Subclasses" Br. Jou Sports Med.

11. http://tarbiah.mam9.com/t49-topic

12. Francis JL. Gleeson M. Pyne DB. Callister R. Clancy RL. "Variation of Salivary (2005): "Immunoglobulins in exercising and sedentary populations" Medicine and Science in Sports and Exercise. Apr.

13. Petibois C, Cazarla G, Deleris G. (2003): "The Biological and metabolic adaptations to 12 months training in elite rowers. Int sports Med.

14. Nieman- D.C, Dumke C.L., Henson, D. Mlhnmulty- L.S, Lind. K. H, Morrow J.D. (2003): "Immune and oxidative changes during and toll owing the western states", National library Medicine.

15. Nehlsen. Cannarella SL. Nieman DC. Fagoaga OR. Kelln WJ. Henson DA. Shannon M. Davis JM, (2000): "Saliva immunoglobutims in elite woman rowers", European Journal of Apptied Physiology. feb.

16. Mashiko T, umeda T, Nakaji S, Sugawara K (2004): "Effects of exercise on the physical condition of college rugby players during summer training camp" . " Br. J. Sports Med.

17. Nieman- D.C, Dumke C.L., Henson, D. Mlhnmulty- L.S, Lind. K. H, Morrow J.D. (2003): "Immune and oxidative changes during and toll owing the western states", National library Medicine.

18. Abu-ElaAbd El-Fattah (1996): The training load and sports man health (positives and risks), edition 01, Dar Elfekr El-Araby, Cairo, Egypt.

19. Hind Abd El- Razik, Samah Hassan Farag (2008): The effect of training using average load on the interferon and some immunoglobulin and its relationship to the level of performance in rhythmic exercises and motor expression, Volume (29), journal of sports science and arts. Helwan University, Cairo, Egypt.

20. Tobias Ibflet, Emil. W, Helle, B, Marie. S, Bete . K (2002): Exercise. Induced change in type 1 cytokine. Producing CD8 tt cells is related to a decrease in memory $t$ cells" . J Applphysiol, Issue. 2.

21. Pederson- B.K \&Toft A.D. (2000): "Effect of exercise on lymphocytes and cytokines". BTSM.

22. Alexandre Moreira, Franco Arsati, YnaraBosco de Oliveira Lima-Arsati, Emerson Franchini, and Vera Cavalcanti de Araujo (2010)" "Effect of a Kickboxing Match on Salivary Cortisol and Immunoglobulin A. Perceptual and Motor Skills" Sport University of São Paulo, Volume 111.

23. Starkia R.L, Rolland. J, And M, Febbraio A. (2001): "Effect of adrenergic blockada on lymphocyte cytokine production at rest and during exercise" Am J. Physiology.

24. Charles Gozzoli, Deter Masson (2006): "IAAF Kids' Athletcs", A team Event for Children, International Association of Athletics federations.

25. Mohammed Abdul Rahman Abdullah Abu Hamid (2006): The effectiveness of minor games program using cooperative learning on improving basic movements for the first stage of basic education, unpublished Master degree thesis, Faculty of Physical Education, University of Alexandria, Egypt.

26. Marwa Youssef Youssef El-Dahshoury (2000): "The effect of minor games proposed program on some physical fitness components and ability to motor learning at the physical education lesson for female pupils in the primary stage", unpublished Master degree thesis, Faculty of Physical Education for Girls, Helwan University, Cairo, Egypt 
